\title{
AOR
}

Selected Papers of \#AolR2020:

The 22nd Annual Conference of the Association of Internet Researchers Virtual Event / 13-16 Oct 2021

\section{REGULATING EXPRESSION AND EQUALITY IN COLLEGIATE ESPORTS}

\author{
Dan L. Burk \\ University of California, Irvine School of Law \\ Elizabeth Rosenblatt \\ University of Tulsa College of Law

\section{Introduction}

Attention to competitive professional computer gaming or "eSports" has grown rapidly over the past decade. (1) The interest in such competitive gaming is not restricted to professional settings, but has extended into collegiate play, where educational institutions now sponsor eSports teams, leagues, and events. Collegiate eSports programs frequently resemble established programs for collegiate physical sports, including scholarships, coaching, and raucous competitive events. Sponsoring these programs helps to attract accomplished students and serves to promote both the general reputation of the sponsoring institutions as well as institutional programs such as certificates or degrees in computer game development.

\section{eSport Equality}

However, the expansion of eSports has been accompanied by concerns regarding the attitudes that attend it; specifically, the online gaming culture from which eSports proceeds displays frequent and persistent harassment of female players. Copious documented research, as well as anecdotal experience, establishes that women are routinely subjected to gender-based harassment in computer games and game-related activity. (2) Instances of harassment have been observed not only in interactions within the virtual environment of computer games but in the discourse that surrounds computer gaming, pervading gaming culture, gaming practice, and the structure of the computer gaming industry. (3)

Suggested Citation (APA): Burk, D. \& Rosenblatt, E. (2021, October). Regulating Expression and Equality in Collegiate eSports. Paper presented at AoIR 2021: The 22nd Annual Conference of the Association of Internet Researchers. Virtual Event: AolR. Retrieved from http://spir.aoir.org. 
It is clear that such misogyny extends to eSports, both at the professional and collegiate levels, and poses a serious legal concern in educational settings. $(4,5,6)$ Law is jurisdictional, and we consider here the issues raised in the United States under Title IX of the Educational Amendments of 1972. Title IX guarantees co-educational equal opportunity to women at all institutions receiving federal funds. To guarantee equality of educational access, Title IX mandates equivalence of resources committed to male and female programming. (7) Consequently, the statute is perhaps best known for its history of ensuring equivalence for both male and female athletes in collegiate sports. Although educational institutions need not sponsor exactly the same activities for men and women, the commitment of resources for such activities must be the same. As eSports expand in higher education, Title IX compliance with resource commitment will be required.

However, equality of educational opportunity does not end with equality in resources. Institutions subject to Title IX are additionally required to maintain a learning environment in which educational opportunities are not impeded by sexual harassment. This includes not only overt acts of discrimination, including explicit sexual harassment, but also the creation or persistence of "hostile environments" that would be detrimental to the inclusion of women. It is already clear that, as eSports are increasingly part of sponsored collegiate activities, association of eSports with gaming misogyny will pose a challenge in this regard. Collegiate eSports sponsors will need to take steps to ensure that female players are afforded the same opportunities as male players and are not deterred or disadvantaged by the type of harassment that is frequently seen in gaming culture.

\section{eSport Expression}

As a legal matter, it is clear that the responsibility for curtailing gender hostility in collegiate eSports lies squarely with the sponsoring institutions. The previous application of Title IX to sponsored sports programs will provide some guidance as to the standards collegiate eSports must meet. At the same time, prior experience with Title IX and physical sports may diverge substantially from its interactions with eSports. Computer games differ significantly from physical sports in their character and affordances. (8) Unlike sports played in physical space, computer games are necessarily mediated by software, which has consistently been held to constitute protected speech under the First Amendment to the United States Constitution, which prohibits governmental regulation "abridging the freedom of speech, or of the press." The audiovisual output of such games has also been held to constitute protected speech.

Thus, the First Amendment poses a constraint on the regulation of eSport computer games under title IX which has not been encountered in past Title IX situations. In particular, the selection, content, and of such games may be exempt from governmental interference through Title IX. This aspect of Title IX compliance for eSports has gone previously unexamined. When universities choose to sponsor lacrosse rather than curling, no one believes they are making an expressive statement. But when universities choose to sponsor League of Legends teams rather than Call of Duty, they are necessarily making an expressive statement. To the extent that choices among 
gaming content may be dictated by the constraints of Title IX, care must be exercised to accommodate both the statutory requirements of educational opportunity and the constitutional requirements for expressive freedom.

In this paper we therefore examine problems of Title IX eSports compliance in light of the First Amendment. We begin by reviewing the development of eSports in the context of sponsored competitive collegiate game play and review the evidence of pervasive misogyny surrounding eSports and gaming culture. We then discuss the application of Title IX to such sponsored activities, including the requirement that educators maintain a learning environment in which educational opportunities are not hampered genderbased harassment. We then examine the intersection between Title IX and the First Amendment, particularly as their association may be shaped by the protected expressive nature of computer games at that intersection. We conclude that while Title IX supports and requires a range of actions to ameliorate gender harassment surrounding collegiate eSports, certain avenues of remediation are restricted or foreclosed by the First Amendment.

\section{Conclusion}

Our analysis here fits squarely within the ambit of the AolR 2021 conference theme of "independence" and the structures of on-line discourse. Here we examine the intersection and balance between conflicting demands for independence: freedom from gender harassment against freedom from governmental intrusion on protected expression. We recognize that our analysis raises a number of additional, significant questions of independence for future research. For example, it seems likely that the culture surrounding computer gaming is even less welcoming to transgender and LGBTQ+ players than it is to cis-gendered women, and this may have implications for Title IX collegiate eSports compliance, raising a set of complex questions beyond the scope of our discussion here. But we offer here the first steps on the path to addressing such questions.

\section{References}

(1) T.L. TAYlor, Raising the StaKes: E-SPORTS AND the PROFESSIONALIZATION OF COMPUTER GAMING (2012).

(2) Jesse Fox \& Wai Yen Tang, Women's Experiences with General and Sexual Harassment in Online Video Games: Rumination, Organizational Responsiveness, Withdrawal, and Coping Strategies, 19 NEW MEDIA \& SoC. 1290 (2017).

(3) Emma Witkowski, Doing/Undoing Gender with the Girl Gamer in HighPerformance Play in FEMINISM IN PLAY (Kishonna L. Gray, Gerald Voorhees \& Emma Vossen eds., 2018). 
(4) Omar Ruvalcaba et al., Women's Experiences in eXports: Gendered Differences in Peer and Spectator Feedback During Competitive Game Play, 42 J. SPORT \& SOC. ISSUES 295 (2018).

(5) Nicolas Taylor \& Bryce Stout, Gender and the Two-Tiered System of Collegiate exports, 37 CRIT. STUD. MEDIA Comm. 451 (2020).

(6) Lindsay Darin, Ryan Voorhis, \& Tara Mahoney, The Playing Experiences of eXports Participants: An Analysis of Hostility and Treatment Discrimination in exports Environments, 2 J. ATHLETE LEV. \& EXP. 26 (2020).

(7) Deborah L. Brake, Getting IN the Game: Title IX and the Women's Sports REVOLUTION (2010).

(8) Dan L. Burk, Owning e-Sports: Proprietary Rights in Professional Computer Gaming, 161 U. PENN. L. REV. 1535 (2013). 